\title{
A Case of Infantile Metachromatic Leukodystrophy
}

\author{
Vaibhav S. Lokhande ${ }^{\mathrm{a}, \mathrm{b}}$, Anil Gaur ${ }^{\mathrm{a}}$
}

\begin{abstract}
Metachromatic leukodystrophy (MLD) is the neurometabolic disease caused by deficiency of enzyme arylsulfatase A resulting in deficiency of sulfatide degradation. The responsible gene is arylsulfatase A gene. We report a case of the infantile MLD that was confirmed by means of enzyme studies, nerve conduction velocity and typical MRI of brain findings.
\end{abstract}

Keywords: Infantile; Metachromatic leukodystrophy; Arylsulfatase A; ARSA gene; MRI brain

\section{Introduction}

Metachromatic leukodystrophy (MLD) is the typical white matter disease which belongs to the lysosomal sphingolipid storage group, and it is inherited in the autosomal recessive way [1]. MLD is caused by the deficiency of enzyme arylsulfatase $\mathrm{A}(A R S A)$ resulting in the deficiency of sulfatide degradation and the target gene is $A R S A$ gene. The accumulation of sulfatide triggers leukodystrophy. The incidence of MLD is reported as about 1 per 100,000 live births in the European population, and is found at even lower rate in Asia [2,3]. Clinically, it shows a wide range of spectrum with respect to the age of onset, the rate of progression and the initial following: 1) the late infantile form of disease that starts before the age of 2 or 3 years, 2) the juvenile form that starts between 2 or 3 and 16 years, and 3 ) the adult form that presents its first symptoms

Manuscript accepted for publication August 12, 2014

a Department of Physical Medicine and Rehabilitation, All India Institute of Physical Medicine and Rehabilitation, K Khadey Road, Haji Ali, Mumbai (W) 400034 , India

${ }^{\mathrm{b}}$ Corresponding Author: Vaibhav S. Lokhande, Department of Physical Medicine and Rehabilitation, All India Institute of Physical Medicine and Rehabilitation, K Khadey Road, Haji Ali, Mumbai (W) 400 034, India.

Email: vlok332@gmail.com

doi: http://dx.doi.org/10.14740/jnr294e after the age of 16 years [4-6].

\section{Case Report}

A 2 years and 6 months old male patient came with chief complaints of developmental delay and generalized tightness which started developing at the age of 1 year, and inability to seat and stand. He had no specific birth history and showed normal pattern of development including independent walking before the onset of symptoms. The developmental regression progressed continuously. His family history was found to be negative. Parents noticed weakness in bilateral lower limb and he was taken to general physician, where he was investigated. Routine investigations were found to be normal except serum calcium level was low. Hence he was treated with calcuim

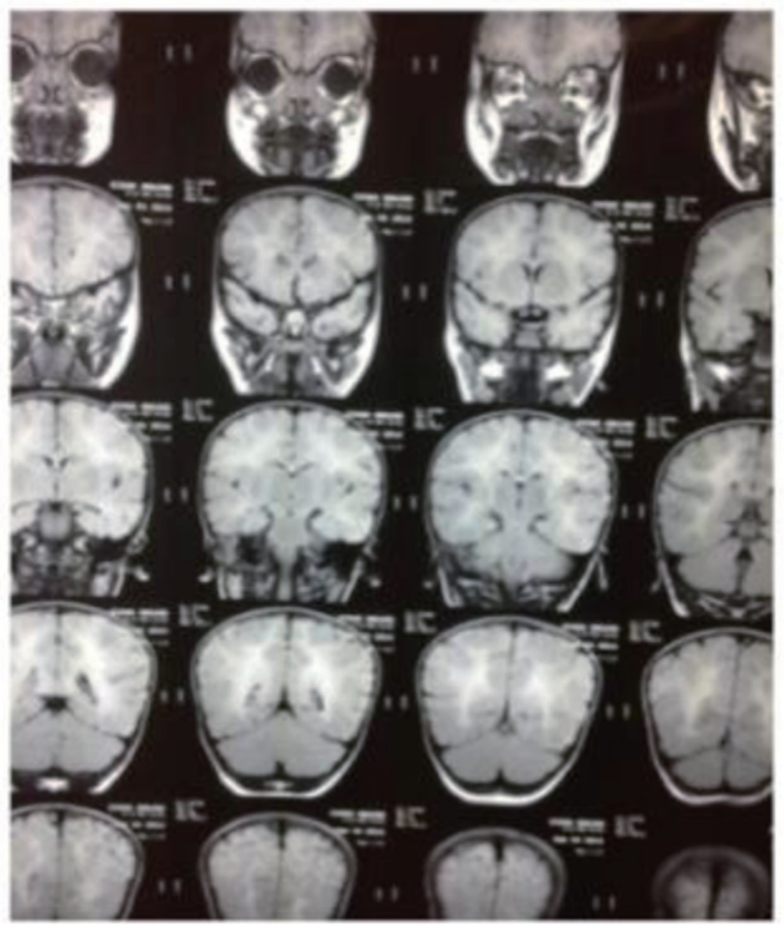

Figure 1. MRI of brain showing T2 hyperintense signals in bilateral fronto-parietal, parieto-occipital white matter. 


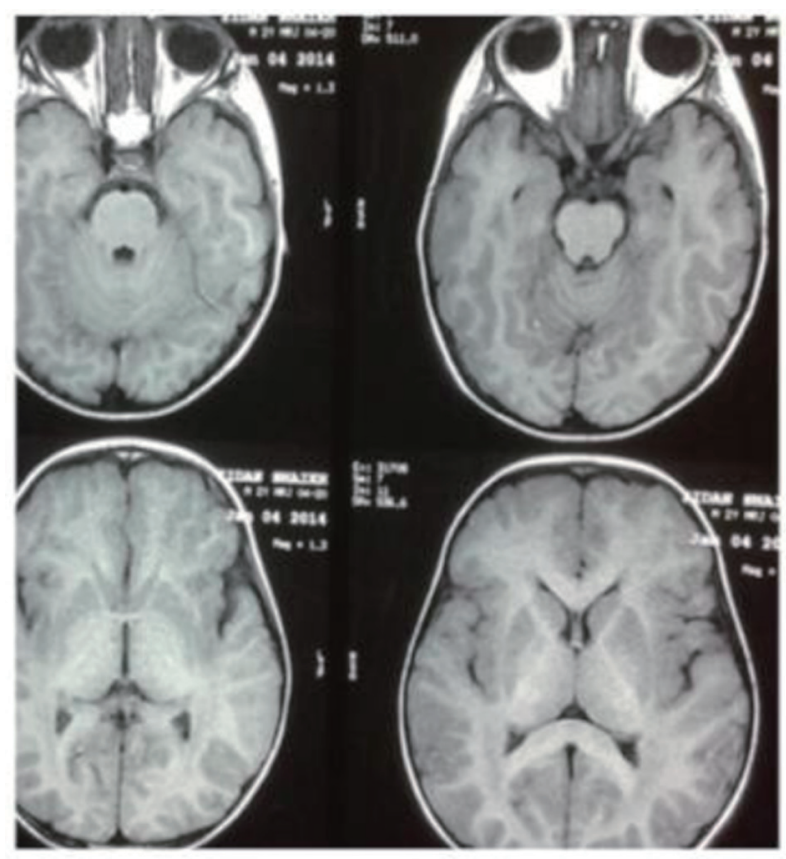

Figure 2. MRI of brain showing T2 hyperintense signals in posterior capsule.

and vitamin-D supplements. Parents noticed no improvement. On clinical examination bilateral knee reflex exaggerated and Babinski's sign was positive. So MRI of brain was done which was suggestive of T2 hyperintense signals in bilateral frontoparietal, parieto-occipital white matter, corona radiata and posterior capsule. This was likely suggestive of dysmylination/ demylination sequalae to MLD (Fig. 1-3).

Nerve conduction velocity study was done for lower limbs weakness which was indicative of bilateral sensory motor neuropathy.

Arylsulfatase A enzyme activity in leukocytes was tested and found to be decreased to $5.3 \%$ of normal control value. Thus, the patient was confirmed to have metachromatic leukodystrophy (method: artificial chromogenic and flurogenic substrates (Fig. 4)).

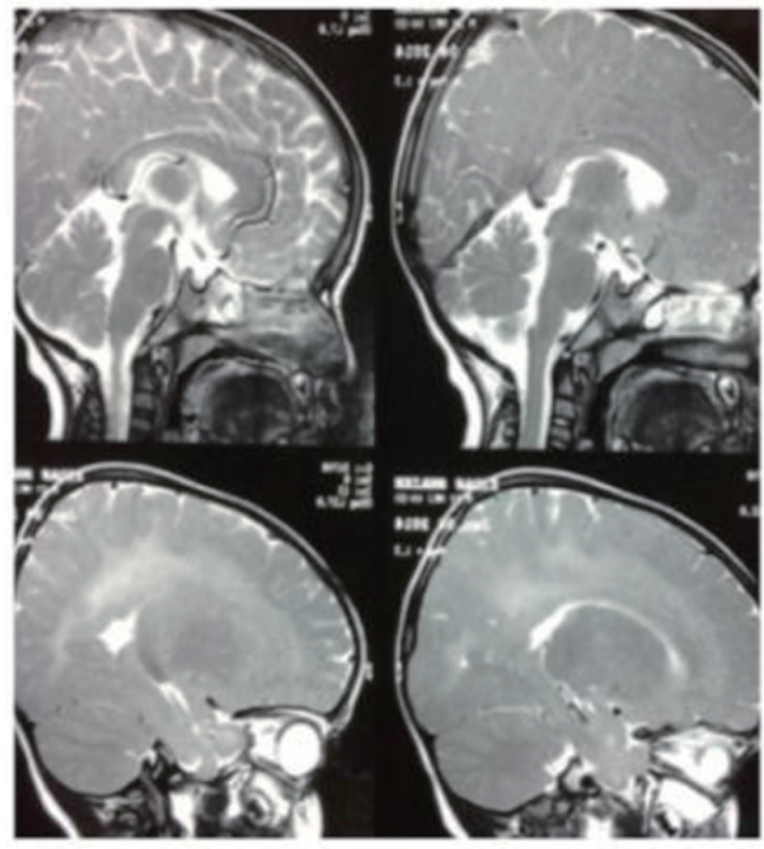

Figure 3. MRI of brain showing T2 hyperintense signals in corona radiata.

\section{Discussion}

MLD is a lysosomal storage disease from the family of leukodystrophies and among the sphingolipidoses it affects the metabolism of sphingolipids. Leukodystrophies affect the growth and/or development of myelin, the fatty covering which acts as an insulator around nerve fibers throughout the central and peripheral nervous systems. MLD involves cerebroside sulfate accumulation. MLD has an autosomal recessive inheritance pattern [7].

There is currently no treatment or cure for MLD and future treatment options are currently being investigated. These include gene therapy, enzyme replacement therapy, substrate reduction therapy and potentially enzyme enhancement ther-

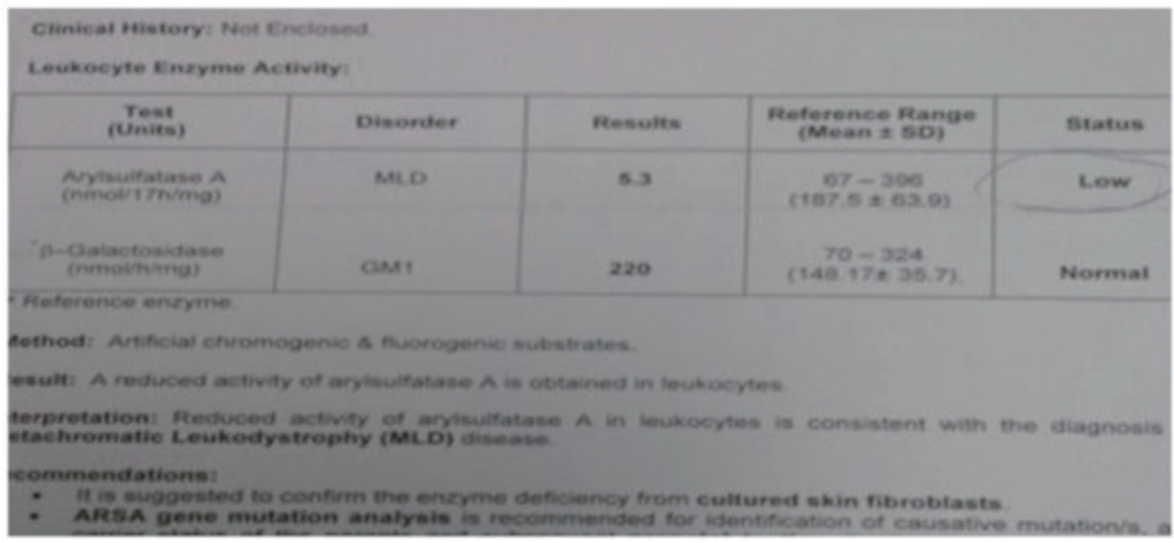

Figure 4. Arylsulfatase A enzyme activity in leukocytes by "artificial chromogenic and flurogenic substrates" method. 


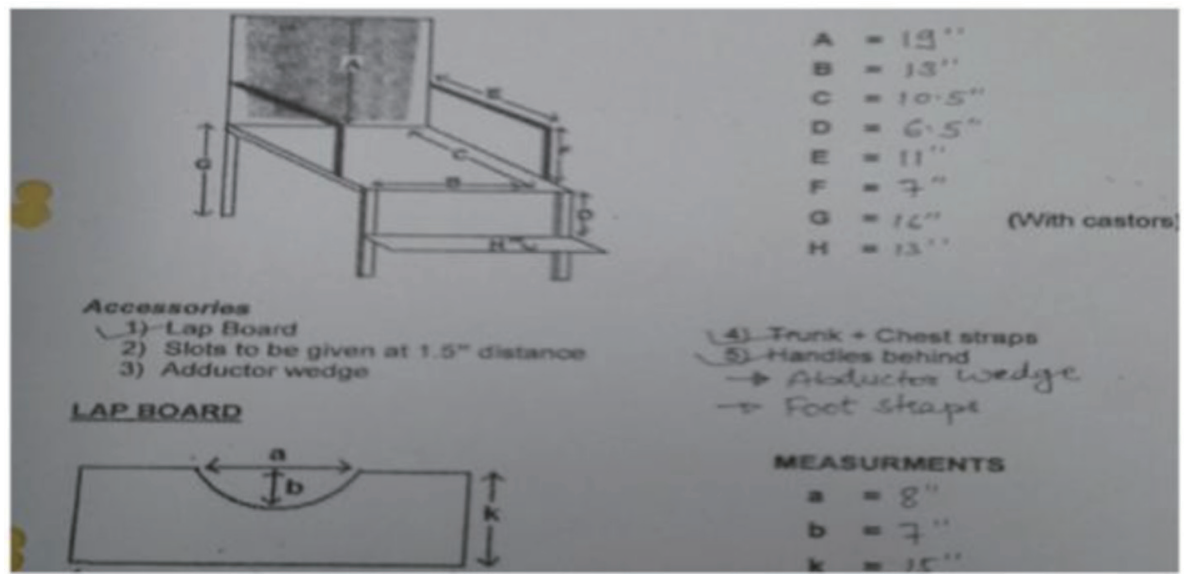

Figure 5. Seating device for patient designed by our institute.

apy.

Our patient is not able to sit, therefore seating device was provided from our institute (Fig. 5). For bilateral lower limb spasticity "knee ankle foot orthosis" was provided. Prognosis was explained and also medical and social counselling was done to parents. We were not able to do $A R S A$ gene testing due to lack of affordability.

\section{References}

1. Sandhoff R, Hepbildikler ST, Jennemann R, Geyer R, Gieselmann V, Proia RL, Wiegandt H, et al. Kidney sulfatides in mouse models of inherited glycosphingolipid disorders: determination by nano-electrospray ionization tandem mass spectrometry. J Biol Chem. 2002;277(23):20386-20398.

2. Heim P, Claussen M, Hoffmann B, Conzelmann E, Gartner J, Harzer K, Hunneman DH, et al. Leukodystrophy incidence in Germany. Am J Med Genet. 1997;71(4):475-
478.

3. Poorthuis BJ, Wevers RA, Kleijer WJ, Groener JE, de Jong JG, van Weely S, Niezen-Koning KE, et al. The frequency of lysosomal storage diseases in The Netherlands. Hum Genet. 1999;105(1-2):151-156.

4. Biffi A, Cesani M, Fumagalli F, Del Carro U, Baldoli C, Canale S, Gerevini S, et al. Metachromatic leukodystrophy - mutation analysis provides further evidence of genotype-phenotype correlation. Clin Genet. 2008;74(4):349357.

5. MacFaul R, Cavanagh N, Lake BD, Stephens R, Whitfield AE. Metachromatic leucodystrophy: review of 38 cases. Arch Dis Child. 1982;57(3):168-175.

6. Lugowska A, Amaral O, Berger J, Berna L, Bosshard NU, Chabas A, Fensom A, et al. Mutations c.459+1G $>$ A and p.P426L in the ARSA gene: prevalence in metachromatic leukodystrophy patients from European countries. Mol Genet Metab. 2005;86(3):353-359.

7. Le Tao, Bhushan Vikas, Hofmann Jeffrey. First Aid for the USMLE Step 1. McGraw-Hill. 2012:117. 